\title{
Selective Deletion of GRK2 Alters Psychostimulant-Induced Behaviors and Dopamine Neurotransmission
}

\author{
Tanya L Daigle*, I,2 , Mark J Ferris ${ }^{3}$, Raul R Gainetdinov ${ }^{4,5,6}$, Tatyana D Sotnikova ${ }^{4}$, Nikhil M Urs', \\ Sara R Jones ${ }^{3}$ and Marc G Caron*, \\ 'Department of Cell Biology, Duke University Medical Center, Durham, NC, USA; ${ }^{2}$ Department of Brain and Cognitive Sciences, McGovern \\ Institute for Brain Research, Massachusetts Institute of Technology, Cambridge, MA, USA; ${ }^{3}$ Department of Physiology and Pharmacology, Wake \\ Forest School of Medicine, Winston-Salem, NC, USA; ${ }^{4}$ Department of Neuroscience and Brain Technologies, Istituto Italiano di Tecnologia, \\ Genova, Italy; ${ }^{5}$ Skolkovo Institute of Science and Technology, Skolkovo, Moscow Region, Russia; ${ }^{6}$ Faculty of Biology and Soil Science, St Petersburg \\ State University, St Petersburg, Russia
}

\begin{abstract}
GRK2 is a G protein-coupled receptor kinase (GRK) that is broadly expressed and is known to regulate diverse types of receptors. GRK2 null animals exhibit embryonic lethality due to a severe developmental heart defect, which has precluded the study of this kinase in the adult brain. To elucidate the specific role of GRK2 in the brain dopamine (DA) system, we used a conditional gene knockout approach to selectively delete GRK2 in DA DI receptor (DIR)-, DA D2 receptor (D2R)-, adenosine 2A receptor (A2AR)-, or DA transporter (DAT)-expressing neurons. Here we show that select GRK2-deficient mice display hyperactivity, hyposensitivity, or hypersensitivity to the psychomotor effects of cocaine, altered striatal signaling, and DA release and uptake. Mice with GRK2 deficiency in D2R-expressing neurons also exhibited increased D2 autoreceptor activity. These findings reveal a cell-type-specific role for GRK2 in the regulation of normal motor behavior, sensitivity to psychostimulants, dopamine neurotransmission, and D2 autoreceptor function.

Neuropsychopharmacology (20I4) 39, 2450-2462; doi:I 0.1038/npp.20I4.97; published online 28 May 2014
\end{abstract}

\section{INTRODUCTION}

Neuronal G protein-coupled receptors (GPCRs) represent a large class of proteins that orchestrate a diverse array of physiological processes critical for maintaining normal brain function. Central to their regulation are a family of G protein-coupled receptor kinases (GRKs) that are actively engaged following agonist-mediated receptor activation and function in part to dampen intracellular signaling via homologous desensitization. Seven GRK family members have been identified to date, four of which (GRKs 2, 3, 5, and 6) are highly expressed and in diverse cellular populations in the brain (Premont and Gainetdinov, 2007). The physiological functions of GRKs 3-6 have been previously examined using isoform-specific $\mathrm{KO}$ mice to reveal critical roles for these kinases in the regulation of muscarinic, dopamine (DA), and opioid receptor function in adult animals (Gainetdinov et al, 2003; Gainetdinov et al, 1999; McLaughlin et al, 2004). In contrast, germline deletion of GRK2 in mice results in hypoplasia of the ventricular myocardium and embryonic lethality (Jaber et al, 1996).

* Correspondence: DrMG Caron or Dr TL Daigle, Department of Cell Biology, Duke University Medical Center, CARL Research Building, Box 3287, Durham, NC 277I0, USA. Tel: + I 9196842364 (MGC) or + 9196814597 (TLD), E-mail: m.caron@cellbio.duke.edu (MCG) or tanyadaigle@gmail.com (TLD)

Received 23 December 2013; revised I5 April 2014; accepted I5 April 2014; accepted article preview online 29 April 2014
This has consequently hampered efforts to understand the physiological importance of GRK2 function in the adult brain, leaving relatively little known.

DA is a catecholamine neurotransmitter involved in a diverse array of functions in mammals, including the control of movement, addiction, emotion, and cognition. Consistent with its vital role as a neuromodulator, dopaminergic dysfunction has been implicated in various pathological states, such as Parkinson's disease, Huntington's disease, Tourette's syndrome, and attention deficit and hyperactivity disorder (Beaulieu and Gainetdinov, 2011). Two distinct classes of DA-responsive GPCRs, D1-like (D1R and D5R) and D2-like (D2R, D3R, and D4R), are expressed within the basal ganglia and signal through opposing G-proteindependent pathways following activation by DA (Bateup et al, 2008). Previous work from our lab also suggests that striatal D2 receptors signal in a G-protein-independent manner via the scaffolding protein $\beta$ arrestin- 2 to modulate striatal protein kinase $\mathrm{B}$ (Akt) and GSK3 $\beta$ signaling (Beaulieu et al, 2005; Beaulieu et al, 2007). Genetic and/or pharmacological disruption of downstream effectors engaged by DA receptors (eg, DA- and cAMP-regulated phosphoprotein of molecular weight $32 \mathrm{kDa}$ (DARPP-32) and GSK $3 \beta$ ) robustly alters motor behavior and sensitivity to antipsychotic and psychostimulant drugs (Bateup et al, 2010; Beaulieu et al, 2004; Urs et al, 2012). Thus, a more comprehensive understanding of proteins involved in DA receptor signaling may yield valuable mechanistic insights 
regarding several important clinically relevant drugs and provide novel therapeutic targets.

Several studies in heterologous cells have demonstrated that GRK2 can profoundly regulate the trafficking and agonist-induced signaling of D1 and D2 receptors (Ito et al, 1999; Iwata et al, 1999; Namkung et al, 2009a; Namkung et al, 2009b; Sedaghat and Tiberi, 2011; Tiberi et al, 1996). However, evidence for this regulation in vivo or even in systems with more physiologically relevant levels of GRK2 (eg, cultured neurons) remains scarce. Studies utilizing pharmacological interventions that perturb the DA system, such as the psychostimulant cocaine, or potent neurotoxins, such as MPTP (1-methyl-4-phenyl-1,2,3,6-tetrahydropyridine) and 6-hydroxydopamine, have found region-specific alterations in GRK2 levels (Ahmed et al, 2008a; Bezard et al, 2005; Schroeder et al, 2009). Additionally, it was found that fragile X mental retardation protein deficiency in mice causes a coincident increase in GRK2 levels in the frontal cortex and D1R hyperphosphorylation (Wang et al, 2008). Although these studies provide a potential link between GRK2 and the DA system, the physiological consequences of altered GRK2 levels to DA-dependent behaviors remain largely unknown.

To examine the possibility that GRK2 regulates DAdependent behaviors, we generated mice with the conditional deletion of GRK2 in either DA-receptive neurons (D1R-, D2R-, and A2AR-expressing) or in midbrain DA neurons (DA transporter (DAT)-expressing neurons) and utilized behavioral and electrophysiological approaches to determine the impact of GRK2 deletion. Our results reveal cell-type-specific effects of GRK2 deletion on motor behavior, sensitivity to cocaine-induced locomotion, cocaineinduced striatal signaling, and DA uptake inhibition, DA release and uptake, and D2 autoreceptor function.

\section{MATERIALS AND METHODS}

\section{Generation of Experimental Animals}

All animals studies were conducted with an approved protocol from the Duke University Institutional Animal Care and Use Committee in accordance with the National Institutes of Health guidelines. Floxed Grk2 mice were obtained from Dr Gerald Dorn II (Washington University, St Louis, Missouri) (Matkovich et al, 2006) and Rosa26floxed-stop-EYFP reporter mice were obtained from $\mathrm{Dr}$ Brigid Hogan (Duke University, Durham, NC) (Srinivas et al, 2001). The $D 1 R^{\text {cre }}$ (founder line EY262), D2R $R^{\text {cre }}$ (founder line ER44), and $A 2 A R^{\text {cre }}$ (founder line KG139) bacterial artificial chromosome (BAC) transgenic mouse lines were purchased from GENSAT (The Rockefeller University). The $D A T^{\text {cre }}$ knock-in mouse line was obtained from Dr Xiaoxi Zhuang (University of Chicago, Chicago, IL) and has been previously published (Zhuang et al, 2005). Experimental animals were obtained by crossing homozygous floxed Grk2 (129/C57BL/6J) mice to homozygous floxed mice that were also hemizygous (from BAC transgenic lines) or heterozygous (for the knock-in mouse line) for cre. These breedings yielded homozygous floxed Grk2 mice that were also cre-positive (KO animals) and floxed Grk2 littermates (control animals). A summary of the mouse lines generated can be found in Supplementary
Table S1. Drug and experiment-naive adult mice (2-6 months of age) and of mixed sex were used for all studies. Animals were placed on a 12-h light/dark cycle in a temperature- and humidity-controlled environment with ad libitum access to food and water.

\section{Drugs}

Cocaine hydrocholoride, quinpirole hydrochloride, sulpiride, and apomorphine hydrochloride hemihydride were purchased from Sigma-Aldrich, and SKF81297 was purchased from Tocris Biosciences. All drugs were dissolved in isotonic, sterile saline and injected as described at a volume of $10 \mathrm{ml} / \mathrm{kg}$ body weight.

\section{Locomotor Activity and Cocaine Sensitization}

Locomotor activity was measured at 5-min intervals in an automated Omnitech Digiscan open-field $\left(20 \times 20 \mathrm{~cm}^{2}\right)$ apparatus. Animals were tested during the light phase of the cycle and habituated to the room before testing. For the acute cocaine experiments, mice were habituated in the open field for $30 \mathrm{~min}$, removed, injected with the indicated dose of cocaine, and immediately placed back into the apparatus. Sensitization experiments were performed as previously described (Gainetdinov et al, 2003). Briefly, on day 1 of the protocol, mice were injected with the indicated dose of cocaine and placed into the open field. On days $2-5$, mice were injected with the same dose of cocaine and placed back into their home cage. After a 1-day reprieve from treatment, mice were challenged on day 7 with the same dose of cocaine and monitored in the open field for $90 \mathrm{~min}$ postinjection.

\section{Conditioned Place Preference}

Mice were tested using a three-compartment apparatus (Med Associates) as previously described (Daigle and Caron, 2012).

\section{Fast-Scan Cyclic Voltammetry (FSCV)}

Mice received one injection daily of either vehicle or cocaine $(20 \mathrm{mg} / \mathrm{kg}$, i.p.) for 5 consecutive days. Approximately $40 \mathrm{~h}$ after the last injection, mice were killed for slice voltammetry experiments. Note that while this is the same day that mice in the behavioral sensitization experiments received cocaine challenge and locomotor activity assessment, no injections were given to mice in the voltammetry study on day 7. Rather, all drugs were bath applied on brain slices as described in detail below. After killing, multiple coronal slices $(400 \mu \mathrm{m})$ containing the NAc and $\mathrm{CPu}$ were prepared from each animal with a vibrating tissue slicer while immersed in oxygenated artificial cerebrospinal fluid (aCSF) containing (in mM): $\mathrm{NaCl}(126), \mathrm{KCl}(2.5), \mathrm{NaH}_{2} \mathrm{PO}_{4}$ (1.2), $\mathrm{CaCl}_{2}$ (2.4), $\mathrm{MgCl}_{2}$ (1.2), $\mathrm{NaHCO}_{3}$ (25), glucose (11), and L-ascorbic acid (0.4), and $\mathrm{pH}$ was adjusted to 7.4. Once sliced, tissue was transferred to the testing chambers containing bath aCSF $\left(32{ }^{\circ} \mathrm{C}\right)$, which flowed at $1 \mathrm{ml} / \mathrm{min}$. A cylindrical carbon fiber microelectrode $(100-200 \mathrm{mM}$ length, $7 \mathrm{mM}$ radius) and a bipolar stimulating electrode was placed into the dorsolateral $\mathrm{CPu}$, and $\mathrm{DA}$ was evoked by 
a single, rectangular, electrical pulse $(750 \mu \mathrm{A}, 4 \mathrm{~ms})$ applied every $5 \mathrm{~min}$. Extracellular DA was monitored at the carbon fiber electrode every $100 \mathrm{~ms}$ using FSCV by applying a triangular waveform ( -0.4 to +1.2 to $-0.4 \mathrm{~V} v s \mathrm{Ag} / \mathrm{AgCl}$, $400 \mathrm{~V} / \mathrm{s}$ ) (Kennedy et al, 1992). Once the extracellular DA response was stable (ie, did not exceed $10 \%$ variation in peak height for three successive stimulations), a single experiment was performed on each slice containing the $\mathrm{CPu}$ as described below.

After obtaining stable DA to single-pulse stimulation, multiple concentrations of cocaine $(0.3,1.0,3.0,10.0$, and $30.0 \mu \mathrm{M}$ ) were bath applied cumulatively to the slice while continuing single-pulse stimulations every $5 \mathrm{~min}$. Each concentration of cocaine was allowed to stabilize before adding the next concentration (typically $45 \mathrm{~min}$ at each concentration, or eight stimulations). For a separate set of multiple-pulse experiments without cocaine, stimulation parameters were adjusted from the single pulse to include five-pulse stimulations across frequencies that mimic both tonic and phasic firing of DA neurons, including 5, 10, 20, 25 , and $100 \mathrm{~Hz}$ frequencies. Following the five-pulse series of stimulations, the D2R antagonist sulpiride $(10 \mu \mathrm{M})$ was then added to the bath, and DA evoked by single-pulse stimulation was allowed to stabilize to the drug before repeating the multiple-pulse protocol. Immediately following the completion of each experiment, recording electrodes were calibrated by recording their response (in electrical current; nA) to a known concentration of DA in aCSF $(3 \mathrm{mM})$ using a flow-injection system. This value was then used to convert electrical current to DA concentration. Evoked levels of DA were modeled using Michaelis-Menten kinetics, as a balance between release and uptake (Wightman et al, 1988). Michaelis-Menten modeling provides parameters that describe the amount of DA released following stimulation (ie, the peak height of the signal) and the maximal rate of DA uptake $\left(V_{\max }\right)$. We followed standard voltammetric modeling procedures by setting the apparent $K_{\mathrm{m}}$ parameter to $160 \mathrm{nM}$ for each animal based on well-established research on the affinity of DA for the DAT (Wu et al, 2001), while baseline $V_{\max }$ values were allowed to vary as the baseline measure of rate of DA uptake. All modeled data were required to exceed a goodness-of-fit $\geqslant R^{2}=0.98$, and all $V_{\max }$ values fell within an acceptable range of physiological rates of uptake described in previous work. In experiments that incorporated the use of cocaine, the time constant tau (measured as 2/3 return to baseline from peak height) and peak height of the signal was calculated for each concentration of cocaine as a percentage of baseline tau or peak height in order to account for changes in cocaine-induce DA uptake inhibition and release. All voltammetry data were collected and modeled using the Demon Voltammetry and Analysis Software (Yorgason et al, 2011).

\section{Immunohistochemistry}

Staining of free-floating brain sections was performed as previously described (Daigle et al, 2011). Briefly, mice were anesthetized with chloral hydrate $(500 \mathrm{mg} / \mathrm{kg}$ i.p.) and perfused with ice-cold PBS followed by $10 \%$ formalin solution (Sigma Aldrich). Brains were postfixed overnight in $10 \%$ formalin and sectioned $(50 \mu \mathrm{m})$ on a vibratome.
Following permeabilization and blocking, sections were incubated overnight at $4{ }^{\circ} \mathrm{C}$ in one or more of these antibodies: GRK2 (1:500; Santa Cruz Biotechnology), rabbit anti-GFP (1:5000; abcam), chicken anti-GFP (1:500; abcam), DAT (DA transporter) (1:300; Millipore), and met-Enkephalin (1:250; Millipore). Primary antibody was detected with Alexa dye-conjugated secondary antibodies (Life Technologies). Images $(1024 \times 1024$ pixels $)$ were acquired on either a Zeiss LSM-510 confocal microscope or an Olympus FluoView FV1000 confocal microscope.

\section{Western Blotting Analyses}

Determination of phosphoprotein levels in dorsal striatal extracts was performed as previously described (Daigle et al, 2011). Blots were probed with antibodies directed against pT308 Akt $(1: 100)$, Akt $(1: 1500)$, pS9 GSK3 (1:100), or GSK3 (1:500) (all from Cell Signaling Technology), pT34 DARPP-32 (1:300; Phosphosolutions), or DARPP-32 (1:1000; BD Transduction Laboratories). Primary antibodies and direct fluorescent signal from secondary antibodies were detected using an Odyssey Infrared imaging system (LI-COR Biosciences). Phosphoprotein levels were normalized to the corresponding level of total protein and then normalized to the average for the wildtype group $\left(G r k 2^{f / f}\right)$ for each separate experiment.

\section{Tyramide Signal Amplification (TSA) Immunohistochemistry}

Free-floating brain sections were incubated for $5 \mathrm{~min}$ in PBS containing $0.5 \% \mathrm{NaBH}_{2}, 10 \% \mathrm{MeOH}$, and $3 \% \mathrm{H}_{2} \mathrm{O}_{2}$. Sections were then washed in PBS followed by incubation for $15 \mathrm{~min}$ in PBS containing $1.2 \%$ Triton X-100, blocked in PBS containing $5 \%$ normal goat serum, $2 \%$ bovine serum albumin, and $0.2 \%$ Triton X-100 for $1 \mathrm{~h}$, and then incubated overnight at $4{ }^{\circ} \mathrm{C}$ in the indicated antibody. Sections were incubated the following day in either an Alexa-dyeconjugated (Invitrogen) or an HRP-conjugated secondary antibody. The latter was detected by brief incubation with an Alexa488-labelled tyramide reagent (Invitrogen).

\section{Data and Statistical Analyses}

All statistical analyses were performed using the GraphPad Prism 4.0 software (GraphPad Software). The results presented are means with the SEMs. An unpaired Student's $t$-test, one-way ANOVA, or two-way repeated measures (RM) ANOVA was used for the different comparisons as indicated in the text and figure legends.

\section{RESULTS}

\section{Selective GRK2 Deletion Alters Spontaneous Locomotion and Causes a Bidirectional Change in Sensitivity to Cocaine}

To determine whether GRK2 regulates DA receptor function in vivo and, in turn, DA-dependent behaviors, we generated conditional knockout (KO) mice in which GRK2 was selectively deleted from D1R- and D2R-expressing neurons in the murine brain. This was accomplished by crossing 
BAC transgenic mice in which Cre recombinase was driven under the D1R and $\mathrm{D} 2 \mathrm{R}$ promoter elements $\left(D 1 R^{\text {cre }}\right.$ and $D 2 R^{\text {cre }}$ mice, respectively) to mice with a floxed Grk2 locus $\left(G r k 2^{\mathrm{f} / \mathrm{f}}\right)$ to yield conditional KO mice $\left(D 1 R^{\mathrm{cre}} G r k 2^{\mathrm{f} / \mathrm{f}}\right.$ and $D 2 R^{\mathrm{cre}} G r k 2^{\mathrm{f} / \mathrm{f}}$ ) and littermate controls $\left(G r k 2^{\mathrm{f} / \mathrm{f}}\right)$. As D2Rs are expressed in cholinergic neurons within the striatum, striatopallidal neurons, and midbrain DA projection neurons, we expected GRK2 deletion in all of these subpopulations in $D 2 R^{\text {cre }} G r k 2^{\mathrm{f} / \mathrm{f}}$ mice. To confirm Cre-mediated recombination in the intended cellular populations, $D 1 R^{\text {cre }}$ and $D 2 R^{\text {cre }}$ mice were also crossed to Rosa26-EYFP (R26-EYFP) reporter mice, and the brains were fixed and processed for immunostaining against EYFP (anti-GFP) and met-Enkephalin (anti-Enk), a marker of striatopallidal MSNs (Supplementary Figures S1 and S2). We detected Cremediated recombination in the expected brain regions (including strong anti-GFP staining in striatonigral MSNs and cortical layer VI neurons for the $D 1 R^{\text {cre }}$ line and in striatopallidal MSNs for the $D 2 R^{\text {cre }}$ line), consistent with the known expression patterns for endogenous D1 and D2 DA receptors (Supplementary Figures S1A, 1B, S2A, and 2B). In addition, co-labeling of EYFP with Enk was observed in brain sections from $D 2 R^{\text {cre }} \mathrm{R} 26-E Y F P$ but not $D 1 R^{\text {cre }} \mathrm{R} 26$ EYFP mice (Supplementary Figures S1A, S1B S2A, and S2B). Deletion of GRK2 from D1R- and D2R-expressing neurons was also verified using an isoform-specific GRK2 antibody (Ahmed et al, 2008b) and an antibody directed against GFP. Here we observed, in part, deletions of GRK2 within the cortex in the D1R line (Supplementary Figure S1C) and within striatal cholinergic neurons (Supplementary Figure $\mathrm{S} 2 \mathrm{C}$ ) and DA neurons in the D2R line (data not shown). Collectively, these results confirm that $D 1 R^{\mathrm{cre}} G r k 2^{\mathrm{f} / \mathrm{f}}$ and $D 2 R^{\mathrm{cre}} G r k 2^{\mathrm{f} / \mathrm{f}}$ mice exhibit selective deletion of GRK2 in genetically defined D1R- and D2R-expressing cellular populations, respectively.

To investigate the role of GRK2 in DA-dependent behaviors, we first analyzed spontaneous locomotion and the effects of cocaine in mice with the conditional deletion of GRK2 from D1R-expressing neurons. Although no difference in baseline locomotor activity between genotypes was observed in drug-naive mice, the acute administration of cocaine to $D 1 R^{\text {cre }} G r k 2^{\mathrm{f} / \mathrm{f}}$ mice resulted in significantly enhanced psychomotor activation relative to control animals (interaction, $\mathrm{F}_{(23,897)}=2.71, p<0.0001$; genotype, $\mathrm{F}_{(1,897)}=9.39, p=0.0039$; Figure $1 \mathrm{a}$ and $\left.\mathrm{b}\right)$. Analysis of the sum of the distance travelled $90 \mathrm{~min}$ postinjection of 10 or $20 \mathrm{mg} / \mathrm{kg}$ cocaine (i.p.) revealed a 2.5 - and a 1.6 -fold increase, respectively, in the activity of $D 1 R^{\mathrm{cre}} G r k 2^{\mathrm{f} / \mathrm{f}}$ mice compared with control animals (Figure 1c). To determine whether GRK2 deficiency in D1R-expressing neurons altered sensitization to cocaine, we next evaluated the locomotor activity of $D 1 R^{\mathrm{cre}} G r k 2^{\mathrm{f} / \mathrm{f}}$ mice following repeated, daily injections of cocaine $(20 \mathrm{mg} / \mathrm{kg}$, i.p.). As expected, $D 1 R^{\text {cre }} G r k 2^{\mathrm{f} / \mathrm{f}}$ mice were hypersensitive to the initial drug exposure, displaying increased activity on day 1 of the treatment regimen (interaction, $\mathrm{F}_{(23,506)}=2.19, p=0.0012$; genotype, $\mathrm{F}_{(1,506)}=11.05, p=0.0031$; Figure $1 \mathrm{~d}$, left and $p=0.0039$; Figure 1e). However, repeated cocaine injections produced robust sensitization in both genotypes, with no significant difference in activity observed between groups on day 7 (Figure 1d, right and Figure 1e). These data suggest that one function of GRK2 in D1R-expressing neurons may be to negatively regulate psychomotor activation induced by acute cocaine treatment.

In direct contrast to the $\mathrm{D} 1 \mathrm{R}$ conditional $\mathrm{KO}$ line, $D 2 R^{\mathrm{cre}} \mathrm{Grk} 2^{\mathrm{f} / \mathrm{f}}$ mice exhibited increased spontaneous locomotor
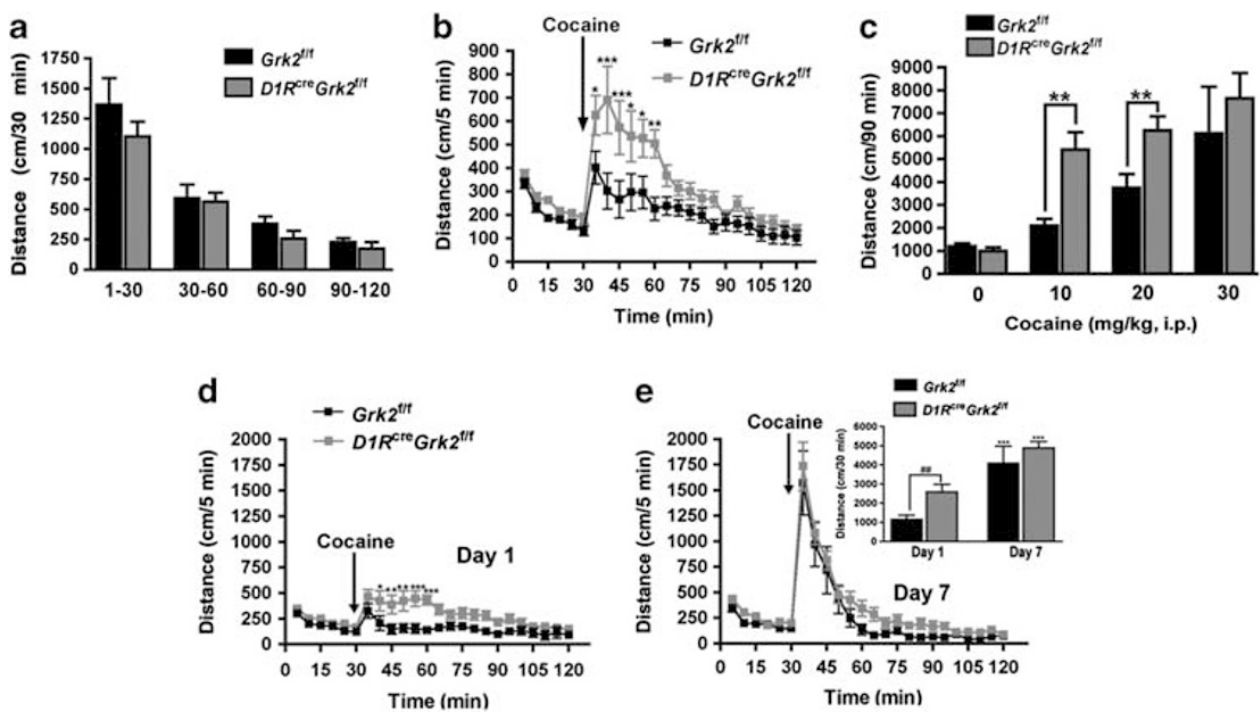

Figure I Deletion of GRK2 from DIR-expressing neurons promotes hypersensitivity to cocaine. (a) Spontaneous locomotor activity of control and $D / R^{\text {cre }} G r k 2^{f / f}$ mice ( $n=9$ mice per group) analyzed in 30-min intervals over a 2-h period. (b) Locomotor activity of mice $\left(G r k 2^{f / f}\right.$ mice, $n=20 ; D / R^{\text {cre }}$ Grk $2^{f / f}$ mice, $n=2 \mathrm{I})$ administered cocaine $(20 \mathrm{mg} / \mathrm{kg}$, i.p.). $* p<0.05$, $* * p<0.0 \mathrm{I}$, $* * * p<0.00 \mathrm{I}$, comparison of drug effect between genotypes by two-way RM

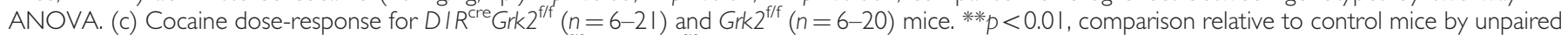
Student's t-test. (d) Cocaine sensitization in $D / R^{\mathrm{cre}} \mathrm{Grk} 2^{\mathrm{flf}}$ and $\mathrm{Grk} 2^{\mathrm{f} / \mathrm{f}}$ mice $(n=8-12$ mice for each group). Locomotor activity of cocaine-treated mice on days I and 7 are shown. ${ }^{*} p<0.05$, $* * * 0.0$ I, **** $p<0.00$ I for comparison of the drug effect between genotypes by two-way RM ANOVA. (e) Cumulative distance traveled by cocaine-treated mice in the first 30 min postinjection of cocaine. ${ }^{\# \#} p<0.0$ I for comparison of the drug effect between genotypes on day I and **** $^{*} p<0.00$ I for comparison of the drug effect on day I vs day 7 by unpaired Student's $t$-test. 
a
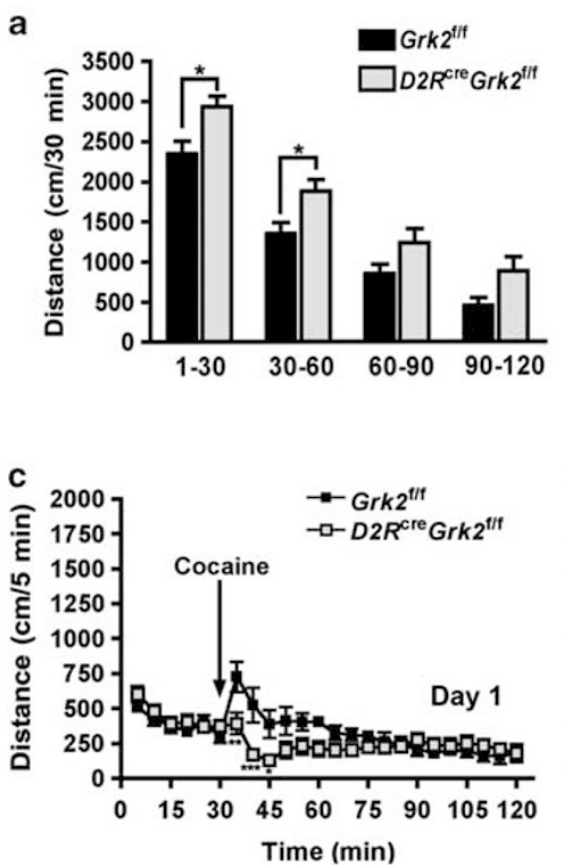
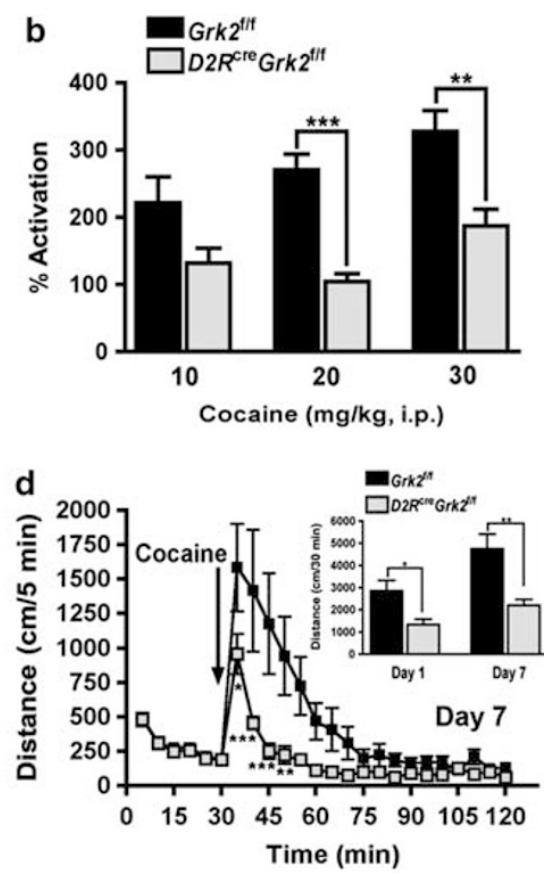

Figure 2 Deletion of GRK2 from D2R-expressing neurons enhances spontaneous locomotion and decreases sensitivity to cocaine. (a) Spontaneous locomotion of Grk2 $2^{\mathrm{fff}}(n=19)$ and $\mathrm{D} 2 R^{\mathrm{cre}} \mathrm{Grk} 2^{\mathrm{fff}}(n=17)$ mice analyzed in 30-min intervals over a 2-h period. * $p<0.05$, comparison between genotypes by

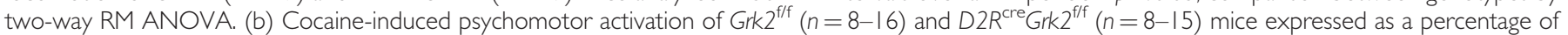
activation (or fold increase) relative to vehicle-treated animals of the same genotype. $* * x<0.01$ and $* * * p<0.001$, comparison of the drug effect between genotypes by unpaired Student's t-test. (c) Cocaine sensitization in D2R ${ }^{\text {cre }} G r k 2^{f / f}$ and Grk2/f mice ( $n=7-8$ mice for each group). Locomotor activity in cocaine-treated mice was analyzed on days I and 7. $* p<0.05$, $* * p<0.01$, **** $p<0.00$ I, comparison of the drug effect between genotypes by two-way RM ANOVA. (d) Cumulative distance traveled by cocaine-treated mice in the first 30 min postinjection of cocaine. $* p<0.05$ and $* * p<0.01$, comparison of the drug effect between genotypes on days I and 7 by unpaired Student's $t$-test. (e) Apomorphine-induced vertical activity in control and D2R ${ }^{\text {cre }}$ Grk ${ }^{\mathrm{f} / \mathrm{f}}$ mice ( $n=10-12$ mice for each group). ${ }^{*} p<0.05$, comparison of the drug effect between genotypes by unpaired Student's $t$-test.

activity (genotype, $\mathrm{F}_{(1,102)}=9.14, p=0.0047$; Figure $2 \mathrm{a}$ ) and reduced responsiveness to acute cocaine $(20 \mathrm{mg} / \mathrm{kg}$, i.p.) treatment (Figure 2b). Analysis of the fold increase in locomotor activity induced by cocaine (fold activation) revealed a robust reduction in responsiveness of $D 2 R^{\text {cre }} G r k 2^{\mathrm{f} / \mathrm{f}}$ mice to multiple independent doses of the stimulant relative to control animals $(p<0.0001$ and $p=0.0033,20$ and $30 \mathrm{mg} / \mathrm{kg}$ doses, respectively; Figure 2b). A cocaine sensitization paradigm was used to determine whether $D 2 R^{\mathrm{cre}} G r k 2^{\mathrm{f} / \mathrm{f}}$ mice could mount a response to a sensitizing regimen of cocaine $\left(20 \mathrm{mg} / \mathrm{kg}\right.$, i.p.). This analysis revealed that $D 2 R^{\mathrm{cre}} G r k 2^{\mathrm{f} / \mathrm{f}}$ mice were significantly less active following cocaine treatment on both days 1 and 7 relative to control animals (day 1: interaction, $\mathrm{F}_{(23,299)}=4.02, p<0.0001$ and day 7: interaction, $\mathrm{F}_{(23,299)}=3.24, p<0.0001$; genotype, $\mathrm{F}_{(1,299)}=$ $8.78, p=0.011$; Figure $2 c$ and d). Interestingly, peak activity (35 min time point) on day $1 v s$ day 7 for conditional KO mice was increased $(393 \pm 77$ vs $960 \pm 145 \mathrm{~cm})$, indicating some degree of sensitization to the locomotor response. However, analysis of the total distance travelled $30 \mathrm{~min}$ postinjection revealed a significant reduction in activity of $D 2 R^{\text {cre }} G r k 2^{\mathrm{f} / \mathrm{f}}$ mice relative to control animals on both days (day 1, $p=0.0167$; and day 7, $p=0.0036$; Figure $2 \mathrm{~d}$ ). These results strongly suggest that GRK2 in D2R-expressing neurons has a role during spontaneous locomotion and is required for the locomotor-stimulating effects of cocaine.

To determine whether the rewarding properties of cocaine were altered by the selective deletion of GRK2, we used a conditioned place preference paradigm. Independent cohorts of $D 1 R^{\mathrm{cre}} G r k 2^{\mathrm{f} / \mathrm{f}}$ and $D 2 R^{\mathrm{cre}} G r k 2^{\mathrm{f} / \mathrm{f}}$ mice were conditioned to two different doses of cocaine $(10$ and $20 \mathrm{mg} / \mathrm{kg}$, i.p.), and their preference for the drug-paired chamber was analyzed. Robust conditioned responses were observed, and no significant differences were identified between genotypes, suggesting that GRK2 in D1R- and D2R-expressing neurons does not have a role in associative learning and cocaine reward (Supplementary Figure S3A and B).

The phenotypes observed in $D 1 R^{\mathrm{cre}} G r k 2^{\mathrm{f} / \mathrm{f}}$ and $D 2 R^{\mathrm{cre}} G r k 2^{\mathrm{f} / \mathrm{f}}$ mice are not due to the BAC transgenes, because both $D 1 R^{\text {cre }}$ and $D 2 R^{\text {cre }}$ hemizygous mice showed no spontaneous locomotor phenotype (Supplementary Figures S1D, 1F S2D, and F) and exhibited normal locomotor activity responses to cocaine (Supplementary Figures S1E, S1F S2E, and S2F). These results argue against any contribution of BAC transgene expression or integration site to DArelated phenotypes in these animals and are consistent with other published observations using these BAC transgenic animals (Bateup et al, 2010; Guzman et al, 2011).

\section{Enhanced DARPP-32 Signaling in the Striatum of Cocaine-Treated $D 1 R^{\mathrm{cre}} G r k 2^{\mathrm{f} / \mathrm{f}}$ Mice}

To determine whether the hypersensitivity phenotype of $D 1 R^{\mathrm{cre}} G r k 2^{\mathrm{f} / \mathrm{f}}$ mice was accompanied by alterations in striatal signaling, we next analyzed phospho-DARPP-32 levels because (1) cocaine has been shown to increase the phosphorylation of DARPP-32 at threonine 34 (T34) selectively in striatonigral neurons (Bateup et al, 2008) and 
a
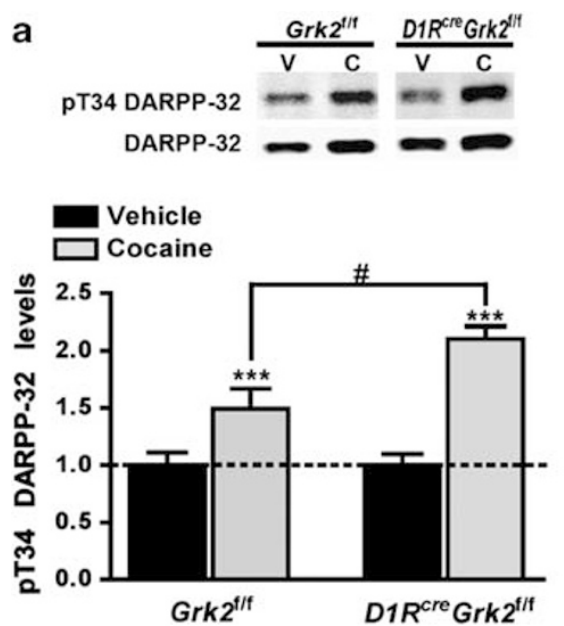

b
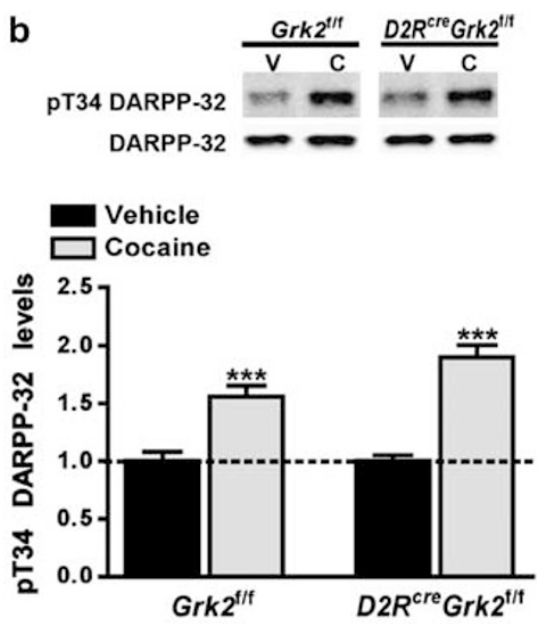

Figure 3 Cocaine-induced DARPP-32 phosphorylation is enhanced in the striatum of $D / R^{c r e} G r k 2^{f / f}$ mice. (a and b) Mice were injected with either vehicle or cocaine $(20 \mathrm{mg} / \mathrm{kg}$, i.p.) and killed 15 min postinjection. PT34 DARPP-32 and total DARPP-32 levels were measured in extracts prepared from the dorsal striatum. Representative western blots (upper panels; $V=$ vehicle and $C=$ cocaine) and the corresponding densitometric analyses are shown. $n=4-8$ mice for each treatment group. PT34 DARPP-32 levels were normalized to the levels of DARPP-32 in the respective striatal extracts. $* * * * 2<0.001$, vehicle vs cocaine treatment within genotypes and ${ }^{\#} p<0.05$ for comparison between genotypes of the drug effect by two-way ANOVA.

(2) because DARPP-32 regulates basal and cocaine-induced locomotion (Bateup et al, 2010). Here we observed that acute cocaine administration promoted a robust increase in striatal pT34 DARPP-32 levels in both genotypes (interaction, $\left.\mathrm{F}_{(1,17)}=34.47, p<0.0001\right)$; however, the effect was significantly enhanced in $D 1 R^{\mathrm{cre}} G r k 2^{\mathrm{f} / \mathrm{f}}$ mice relative to control animals $(210 \pm 11 \%$ vs $149 \pm 17 \%$ of control, respectively; interaction, $\mathrm{F}_{(1,17)}=5.06, p=0.03$; Figure $3 \mathrm{a}$ ). In contrast, a similar magnitude response to cocaine was observed in $D 2 R^{\mathrm{cre}} G r k 2^{\mathrm{f} / \mathrm{f}}$ mice (Figure $3 \mathrm{~b}$ ). Evaluation of basal pT34 DARPP-32 levels in drug-naive $D 1 R^{\mathrm{cre}} G r k 2^{\mathrm{f} / \mathrm{f}}$ and $D 2 R^{\text {cre }} G r k 2^{\mathrm{f} / \mathrm{f}}$ mice revealed no significant differences relative to matched controls (data not shown). These results suggest that GRK2 deletion in D1R-expressing neurons selectively enhances striatal D1R signaling.

To determine whether D2R-mediated Akt and GSK3 signaling in striatopallidal neurons was disrupted by selective GRK2 deletion, we analyzed the levels of phosphorylated threonine 308 (T308) Akt and serine 9 (S9) GSK3 in the striatum of both conditional KO lines. This analysis revealed no significant differences in the basal levels of striatal pT308 Akt and pS9 GSK3 in $D 1 R^{\mathrm{cre}} G r k 2^{\mathrm{f} / \mathrm{f}}$ and $D 2 R^{\text {cre }} G r k 2^{\mathrm{f} / \mathrm{f}}$ mice relative to matched control animals (Supplementary Figure S4A-D). Furthermore, we observed no differences between genotypes in striatal Akt and GSK3 signaling following acute cocaine exposure (data not shown). These results suggest that GRK2 deficiency in D1R- or D2R-expressing neurons does not alter $\beta$ arrestin-2dependent D2R signaling in striatopallidal neurons, and appear to be consistent with the observation that GRK2 phosphorylation is not required for the association of D2R with $\beta$ arrestin-2 (Namkung et al, 2009a).

\section{$D 1 R^{\mathrm{cre}} G r k 2^{\mathrm{f} / \mathrm{f}}$ Mice Exhibit Enhanced DA Release, Uptake, and Sensitivity to Cocaine}

To investigate whether GRK2 deficiency in D1R- or D2Rexpressing neurons caused perturbations to the DA system, we measured evoked DA release and uptake using FSCV in dorsal striatal slices prepared from the conditional KO mice. We observed that, in slices from drugnaive $D 1 R^{\mathrm{cre}} G r k 2^{\mathrm{f} / \mathrm{f}}$ mice, electrically evoked DA release (either to single or multiple stimuli) was robustly increased ( $\sim 2$-fold at each frequency) relative to that measured in slices from control animals (genotype, $\mathrm{F}_{(1,30)}=24.08$, $p=0.0027$; Figure $4 \mathrm{a}$ and $\mathrm{b}$ ). Additionally, as shown in Figure $4 \mathrm{c}$, we found that the maximal rate of DA uptake $\left(V_{\max }\right)$ was dramatically increased in slices from $D 1 R^{\mathrm{cre}} G r k 2^{f / \mathrm{f}}$ mice $(p=0.038)$. This robust increase in $V_{\max }$ levels was similar to what we frequently observe in cocainetreated wild-type animals (data not shown) and may be due to an increase in cell-surface DAT levels as has been previously described for cocaine (Brown et al, 2001; Daws et al, 2002).

To determine whether $D 1 R^{\mathrm{cre}} G r k 2^{\mathrm{f} / \mathrm{f}}$ mice were also hypersensitive to cocaine at the neurochemical level, we measured evoked DA release in the presence of cocaine $(10 \mu \mathrm{M})$ in slices from both genotypes. This analysis revealed a significant increase in evoked DA levels in striatal slices prepared from $D 1 R^{\mathrm{cre}} G r k 2^{\mathrm{f} / \mathrm{f}}$ mice $(p=0.03$; Figure $4 \mathrm{~d})$. Interestingly, we did not observe a difference in the rate of DA uptake inhibition $(\tau)$ between genotypes (data not shown), indicating that GRK2 deficiency in D1Rexpressing neurons does not alter the effectiveness of cocaine at blocking DA reuptake.

As D2 autoreceptors present on DA neurons have been shown to tightly regulate striatal DA release (Bello et al, 2011), we next investigated whether the neurochemical phenotype observed in $D 1 R^{\text {cre }} G r k 2^{f / f}$ mice was due to altered D2 autoreceptor activity. Evoked DA release in striatal slices was measured in the presence of the D2R antagonist sulpiride $(10 \mu \mathrm{M})$ and expressed as a percentage of the baseline value (ie, release at one pulse; Figure 4e). Here we observed that sulpiride did not affect DA release in sections prepared from either genotype. To further evaluate D2 autoreceptor function in this mouse line, we measured 
a

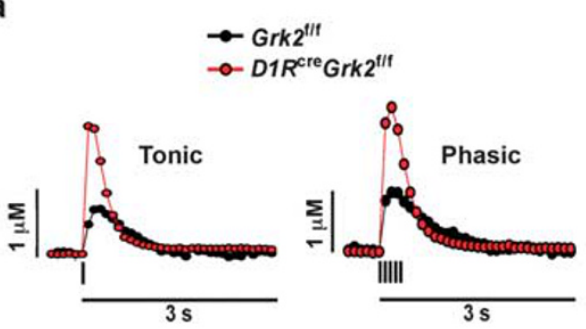

C

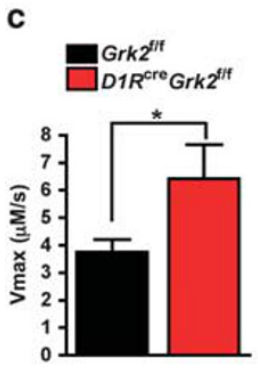

d

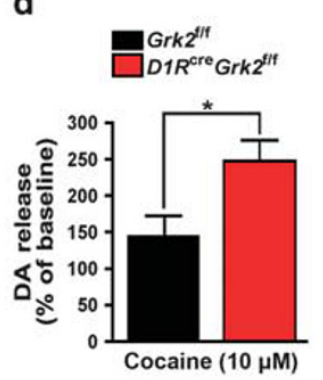

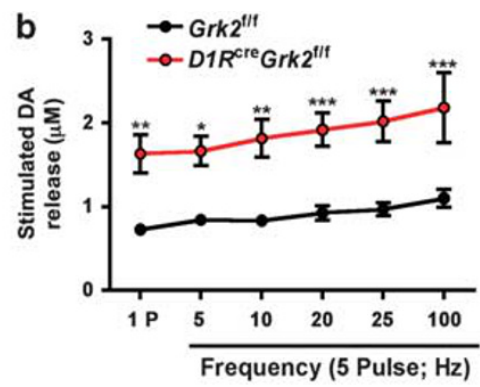

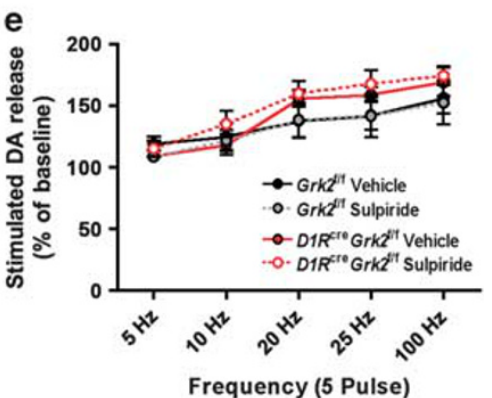

Figure 4 Enhanced baseline and cocaine-induced DA release in $D / R^{c r e} G r k 2^{f / f}$ mice. (a) Representative DA traces (no drug applied) from electrical stimulations that mimic tonic (one pulse) and phasic (five pulses at $25 \mathrm{~Hz}$ ) firing of DA neurons in slices prepared from drug-naive Grk2 ${ }^{\mathrm{f} / \mathrm{f}}$ (black) and $D / R^{\text {cre }} G r k 2^{f / f}$ mice (red). (b) Frequency-DA response curves for slices from control and $D / R^{\text {cre }} G r k 2^{f / f}$ mice $(n=3-5$ mice for each group). * $p<0.05$,

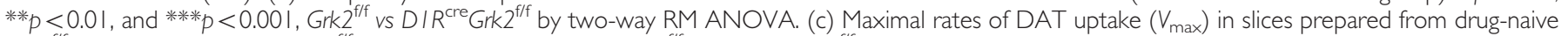
$G_{r k} 2^{f / f}(n=\mid I)$ and $D / R^{c r e} G r k 2^{f / f}(n=8)$ mice. ${ }^{*} p<0.05$, Grk2 $2^{f / f}$ vs $D / R^{\text {cre }} G r k 2^{f / f}$ by unpaired Student's $t$-test. (d) Cocaine response (expressed as percentage of predrug baseline) demonstrates the relationship between bath-applied cocaine $(10 \mu \mathrm{M})$ and electrically stimulated DA release. Slices were prepared from drug-naive Grk $2^{f / f}(n=5)$ and $D / R^{\text {cre }} G r k 2^{f / f}(n=4)$ mice. ${ }^{*} p<0.05$, Grk2 $2^{\mathrm{f} / \mathrm{f}}$ vs $D / R^{\text {cre }}$ Grk2 $2^{\mathrm{f} / \mathrm{f}}$ by unpaired Student's $t$-test. (e) Frequencyresponse curves (expressed as percentage of one-pulse stimulation) before (solid lines) and after (dotted lines) bath application of sulpiride (I $0 \mu \mathrm{M})$. $n=4-6$ mice for each group.

a

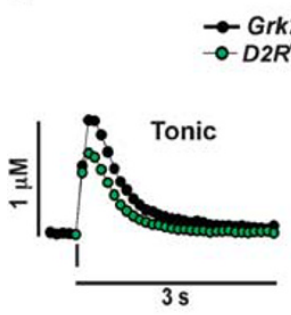

C

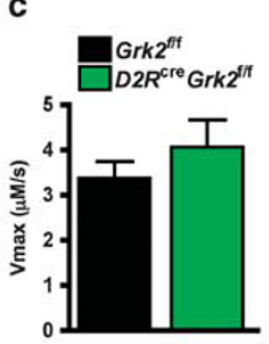

b

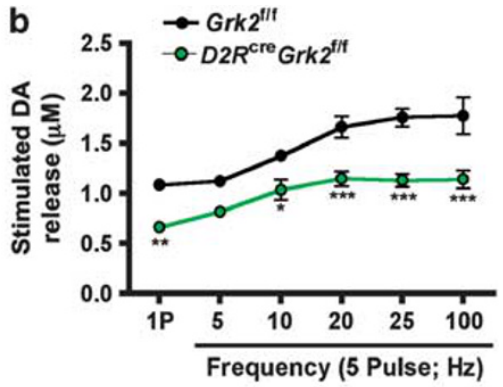

Figure 5 Depressed baseline DA release and increased D2 autoreceptor activity in D2R ${ }^{\text {cre }}$ Grk2 $2^{\mathrm{f} / \mathrm{f}}$ mice. (a) Representative DA traces (no drug applied) from electrical stimulations that mimic tonic and phasic firing of DA neurons in slices prepared from drug-naive Grk $2^{\mathrm{fff}}$ (black) and D2R ${ }^{\mathrm{cre}} \mathrm{Grk} 2^{\mathrm{flf}} \mathrm{mice}$ (green). (b) Frequency-DA response curves for control and conditional KO mice ( $n=4-5$ mice for each group). $* p<0.05$, *** $p<0.01$, and $* * * * 2<0.001$, Grk $2^{\mathrm{f} / \mathrm{f}} \mathrm{vs}$ $D 2 R^{c r e} G r k 2^{f / f}$ mice by two-way RM ANOVA. (c) Maximal rates of DAT uptake in drug-naive Grk2 $2^{f / f}(n=6)$ and D2R $R^{c r e} G r k 2^{\text {f/f }}(n=10)$ mice. (d) Frequencyresponse curves before (solid lines) and after (dotted lines) bath application of sulpiride (I0 $\mu \mathrm{M}) . n=4-7$ mice for each group. *** $p<0.0$ I and $* * * * 0<0.00$ I, vehicle vs sulpiride-treated $D 2 R^{\text {cre }} \mathrm{Grk}^{\mathrm{flf}}$ mice by two-way RM ANOVA. 

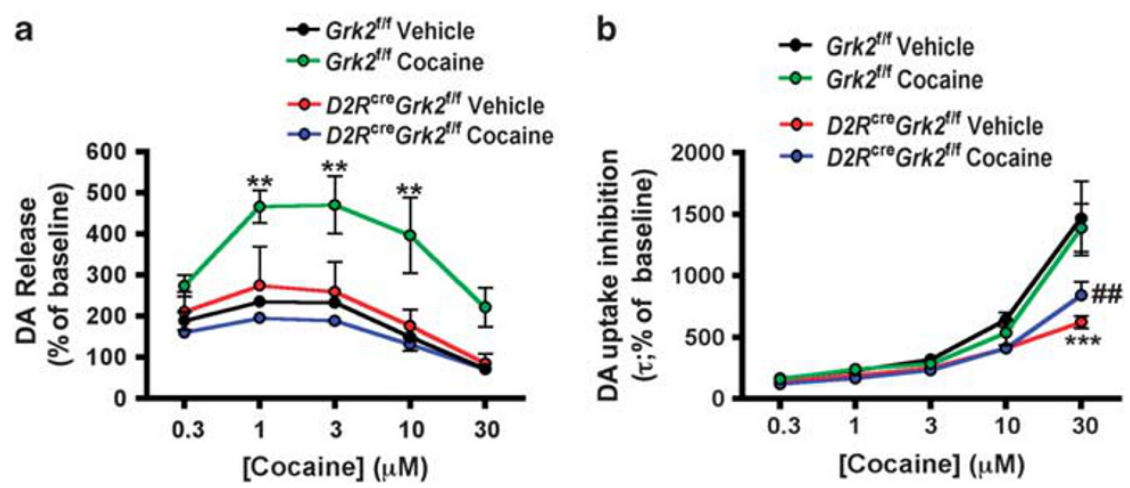

Figure 6 Reduced cocaine-induced sensitization of DA release and inhibition of DA uptake in D2R ${ }^{\text {cre }}$ Grk ${ }^{\text {f/f }}$ mice. (a and b) Cocaine concentrationresponse curves in slices from Grk ${ }^{f / f}(n=3)$ and $D 2 R^{\text {cre }} G r k 2^{f / f}$ mice treated acutely (vehicle group) or exposed repeatedly to cocaine (cocaine group) demonstrate the relationship between bath-applied cocaine $(I 0 \mu \mathrm{M})$ and electrically stimulated DA release (a) or DA uptake inhibition (b). $* * *<0.01$, vehicle vs cocaine-treated Grk2 $2^{\mathrm{flf}}$ mice in panel (a). **** $p<0.00 \mathrm{I}$, comparison of acute cocaine treatment groups (black vs red in panel (b) by two-way RM ANOVA. ${ }^{\# \#} p<0.01$, cocaine-sensitized Grk2 ${ }^{f / f}$ mice vs cocaine-sensitized D2R $R^{\text {cre }}$ Grk $2^{\mathrm{flf}}$ mice (green vs blue in panel (b) by two-way RM ANOVA.

evoked DA release in the presence of quinpirole, a direct $\mathrm{D} 2 \mathrm{R}$ agonist. This analysis revealed no significant differences in quinpirole-induced inhibition of DA release between genotypes, regardless of treatment history (Supplementary Figure S5). Collectively, these results strongly suggest that GRK2 deficiency in D1R-expressing neurons does not alter D2 autoreceptor function.

\section{Reduced DA Release and Increased D2 Autoreceptor Activity in $D 2 R^{\text {cre }} G r k 2^{\mathrm{f} / \mathrm{f}}$ Mice}

Conversely, measurement of DA release evoked by a single or multiple stimuli in slices prepared from drug-naive $D 2 R^{\text {cre }} G r k 2^{\mathrm{f} / \mathrm{f}}$ mice revealed a robust decrease in baseline DA release relative to that measured in control slices (genotype, $\mathrm{F}_{(1,35)}=39.35, p=0.0004$; Figure $5 \mathrm{a}$ and $\mathrm{b}$ ). The depression of baseline DA levels was not due to alterations in the rate of DA uptake, because measured $V_{\max }$ levels were similar in slices between $D 2 R^{\text {cre }} G r k 2^{\mathrm{f} / \mathrm{f}}$ and control animals (Figure 5c). To determine whether altered D2 autoreceptor receptor activity in $D 2 R^{\mathrm{cre}} G r k 2^{\mathrm{f} / \mathrm{f}}$ mice may underlie the hypodopaminergia phenotype, we bath applied sulpiride to slices prepared from drug-naive mice of both genotypes following electrical stimulation. As expected, stimulated $\mathrm{DA}$ release in $D 2 R^{\mathrm{cre}} G r k 2^{\mathrm{f} / \mathrm{f}}$ slices was reduced relative to controls (solid lines, black $v s$ green; interaction, $\mathrm{F}_{(4,40)}=$ $4.95, \quad p=0.0025 ; \quad$ genotype, $F_{(1,40)}=22.08, \quad p=0.0008$; Figure 5d). But interestingly, while sulpiride treatment had no effect in control slices, D2 autoreceptor antagonism relieved the blunted DA release observed in KO slices (dashed $v s$ solid green lines; interaction, $\mathrm{F}_{(4,32)}=2.74$, $p=0.04$; genotype, $\mathrm{F}_{(1,32)}=28.98, p=0.0007$; Figure $5 \mathrm{~d}$ ). These findings suggest that under basal conditions, GRK2 regulates D2 autoreceptor function in this cell population, and the absence of this kinase leads directly to increased receptor activity and dampened evoked DA release.

\section{$D 2 R^{\text {cre }} G r k 2^{\text {f/f }}$ Mice Exhibit Reduced Neurochemical Sensitivity to Cocaine}

We next examined whether the deficiency of GRK2 in D2Rexpressing neurons altered sensitivity to cocaine at the neurochemical level. For these studies, mice were injected with either vehicle or cocaine $(20 \mathrm{mg} / \mathrm{kg}$, i.p.) once daily for 5 consecutive days, and on day 7 (approximately $40 \mathrm{~h}$ after the last injection) striatal slices were prepared from cocainesensitized mice (green and blue groups; Figure 6) and vehicle-treated control animals (black and red groups; Figure 6). Cocaine was then bath applied to slices from both treatment groups, and evoked DA release was measured. As expected, repeated drug administration to control mice resulted in a robust dose-dependent enhancement in cocaine-induced DA release and overflow (black vs green lines; genotype, $\mathrm{F}_{(1,16)}=15.42, p=0.017$; Figure $6 \mathrm{a}$ and $\mathrm{b}$ ). In contrast, cocaine at all concentrations tested did not augment evoked DA release in sections from sensitized$D 2 R^{\text {cre }} G r k 2^{\text {f/f }}$ mice (red $v s$ blue lines; Figure 6a). Additionally, we analyzed the relationship between increasing concentrations of bath-applied cocaine and rates of DA uptake. These measurements revealed that cocaine was less effective at inhibiting DA uptake in $D 2 R^{\text {cre }} G r k 2^{\mathrm{f} / \mathrm{f}}$ mice regardless of vehicle or cocaine treatment (vehicle groups: interaction, $\mathrm{F}_{(4,28)}=6.01, p=0.0013$; genotype, $\mathrm{F}_{(1,28)}=$ 8.31, $p=0.02$ and cocaine groups: interaction, $\mathrm{F}_{(4,20)}=$ $5.28, p=0.0046$; Figure $6 \mathrm{~b}$ ). These findings strongly suggest that GRK2 in D2R-expressing neurons is required for cocaine-induced sensitization of DA release and cocainemediated inhibition of DA uptake in the striatum.

\section{$D A T^{\mathrm{cre}} G r k 2^{\mathrm{f} / \mathrm{f}}$ Mice are Hyperactive and Less Sensitive to Acute Cocaine Treatment}

Because $D 2 R^{\text {cre }} G r k 2^{\mathrm{f} / \mathrm{f}}$ mice have GRK2 deleted in both postsynaptic DA-receptive neurons (ie, striatopallidal MSNs) and presynaptic DA neurons, we next sought to discern the role of GRK2 in these two distinct cell types using a genetic approach. We generated two independent lines of conditional KO mice in which GRK2 was selectively deleted from either presynaptic DA neurons or postsynaptic A2AR-expressing striatopallidal MSNs. This was accomplished by crossing Grk $2^{\text {fff }}$ mice to either $D A T^{\text {cre }}$ or $A 2 A R^{\text {cre }}$ mouse lines to yield conditional KO mice (DAT ${ }^{\mathrm{cre}} G r k 2^{\mathrm{f} / \mathrm{f}}$ and $\left.A 2 A R^{\text {cre }} G r k 2^{\mathrm{f} / \mathrm{f}}\right)$ and control littermates. Immunostaining with cell-type-specific markers (DAT and DARPP-32) 
a

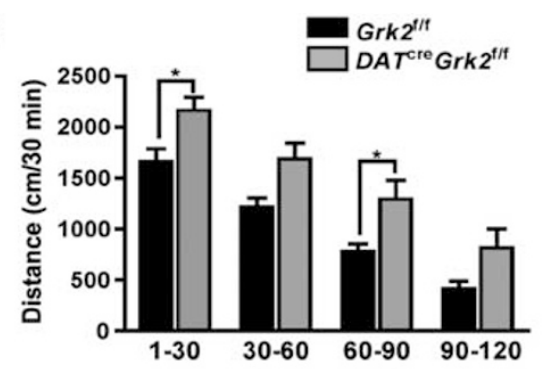

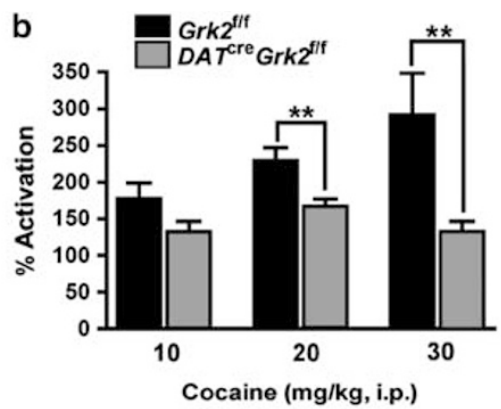

C
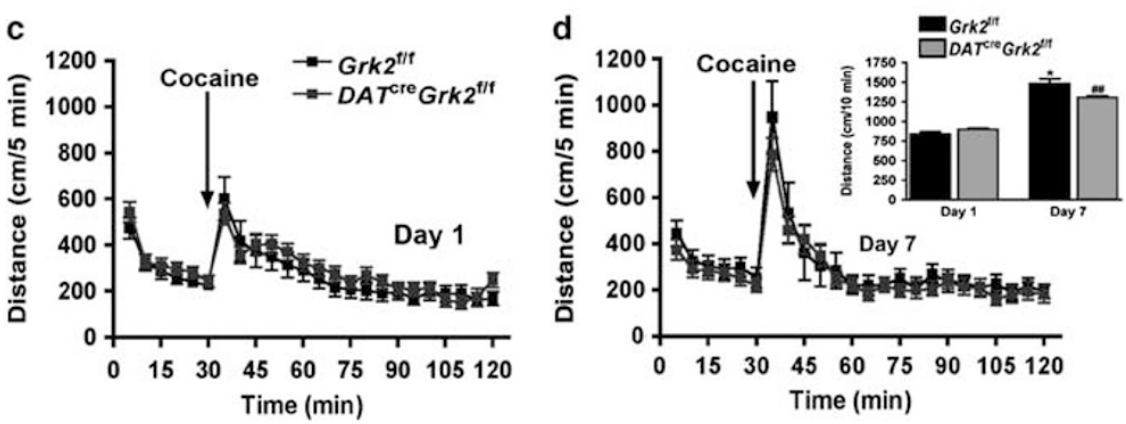

Figure 7 DAT $T^{\text {cre }} G r k 2^{f / f}$ mice exhibit enhanced spontaneous locomotion and reduced sensitivity to cocaine. (a) Spontaneous locomotion of Grk2 $2^{f / f}$ and $D A T^{\text {cre }}$ Grk ${ }^{f / f}$ ( $n=20$ mice per group) mice was analyzed in 30-min intervals over a 2-h period. * $p<0.05$, comparison between genotypes by two-way RM ANOVA. (b) The change in locomotor activity (expressed as a percentage) of Grk $2^{f / f}(n=6-20)$ and DAT $T^{\text {cre }}$ Grk $2^{f / f}(n=8-20)$ mice following acute cocaine treatment. $* p<0.05$ and $* *$ $p<0.01$, comparison of the drug effect between genotypes by unpaired Student's t-test. (c) Cocaine sensitization in DAT ${ }^{\text {cre }}$ Grk $^{\mathrm{f} / \mathrm{f}}$ and $G r k 2^{f / f}$ mice ( $n=\mid 9-21$ mice for each group). Locomotor activity in cocaine-treated mice on days I and 7 are shown. (d) Cumulative distance traveled by cocaine-treated mice in the first 10 min postinjection of cocaine. ${ }^{*} p<0.05$ and ${ }^{\# \#} p<0.01$, comparison of the drug effect between days 1 and 7 in each respective genotype by unpaired Student's t-test.

confirmed Cre-mediated recombination in the intended cell populations (Supplementary Figures S6A and S7). Interestingly, we did not observe GRK2 expression in A2ARexpressing MSNs within the dorsal striatum or a notable loss of GRK2 staining in the striatum of $A 2 A R^{\text {cre }} G r k 2^{\mathrm{f} / \mathrm{f}} \mathrm{KO}$ mice (Supplementary Figure S7A and data not shown). These results strongly suggest that GRK2 is not expressed at measurable levels in MSNs and are consistent with the recent observation that GRK2 is most highly expressed in cholinergic interneurons within the striatum (Bychkov et al, 2012; Daigle and Caron, 2012).

Similar to the $D 2 R^{\mathrm{cre}} G r k 2^{\mathrm{f} / \mathrm{f}}$ line, $D A T^{\mathrm{cre}} G r k 2^{\mathrm{f} / \mathrm{f}}$ mice were hyperactive over a 2 -h period relative to control animals (genotype, $\mathrm{F}_{(1,114)}=9.20, p=0.0043$; Figure $7 \mathrm{a}$ ). In addition to the marked hyperactivity, DAT $T^{\text {cre }} G r k 2^{\mathrm{f} / \mathrm{f}}$ mice also exhibited reduced sensitivity to acute cocaine administration. Analysis of the fold activation induced by cocaine over a 90 -min period revealed a striking reduction in responsiveness of $D A T^{\text {cre }} G r k 2^{\mathrm{f} / \mathrm{f}}$ mice to two doses of the stimulant relative to control animals $(p=0.0045$ and $p=0.0097,20$ and $30 \mathrm{mg} / \mathrm{kg}$ doses, respectively; Figure $7 \mathrm{~b}$ ). In contrast, analysis of locomotor activity following repeated cocaine injections revealed no significant differences between genotypes on days 1 or 7 (Figure 7c and d). Additionally, no difference in cocaine reward was observed in the conditioned place preference paradigm (Supplementary Figure S3C). To confirm that mice heterozygous for the $D A T^{\text {cre }}$ allele alone do not have altered locomotor behavior, we performed open field studies on DAT $T^{\text {cre }}$ heterozygous animals and wild-type littermates (Supplementary Figure S6). We observed no differences in the total distance travelled by drug-naive or cocaine-treated animals, indicating that the insertion of the IRES-Cre at the endogenous DAT locus does not significantly alter locomotor behavior (Supplementary Figure S6B-D). Taken together, these results indicate that GRK2 in DA neurons has a critical role in the regulation of spontaneous locomotion and acute cocaine-induced psychomotor activation.

\section{$A 2 A R^{\text {cre }} G r k 2^{\mathrm{f} / \mathrm{f}}$ Mice Exhibit Normal Locomotor Behavior and Sensitivity to Cocaine}

Although we were unable to detect appreciable GRK2 expression in A2AR-expressing striatal MSNs (Supplementary Figures S7 and S8), we could not exclude the possibility that an extremely low, yet functionally relevant level of GRK2 was present in this cell population. We therefore performed the same battery of behavioral experiments in $A 2 A R^{\text {cre }} G r k 2^{\mathrm{f} / \mathrm{f}}$ mice as with the other conditional KO lines (Figure 8). However, analysis of spontaneous locomotor activity revealed no significant differences between genotypes (Figure 8a and c). Further studies with cocaine also revealed no significant differences between genotypes in sensitivity to either an acute cocaine exposure or to a sensitizing regimen of cocaine (Figure $8 \mathrm{~b}-\mathrm{d}$ ). Additionally, cocaine-induced conditioned place preference was unaltered in $A 2 A R^{\mathrm{cre}} G r k 2^{\mathrm{f} / \mathrm{f}}$ mice (Supplementary Figure S3D). These results strongly suggest that the hyperactivity and hyposensitivity to cocaine phenotypes observed in $\mathrm{D} 2 \mathrm{R}^{\mathrm{cre}} \mathrm{Grk} 2^{\mathrm{f} / \mathrm{f}}$ mice are not due to a deficiency of GRK2 within postsynaptic striatopallidal MSNs. 

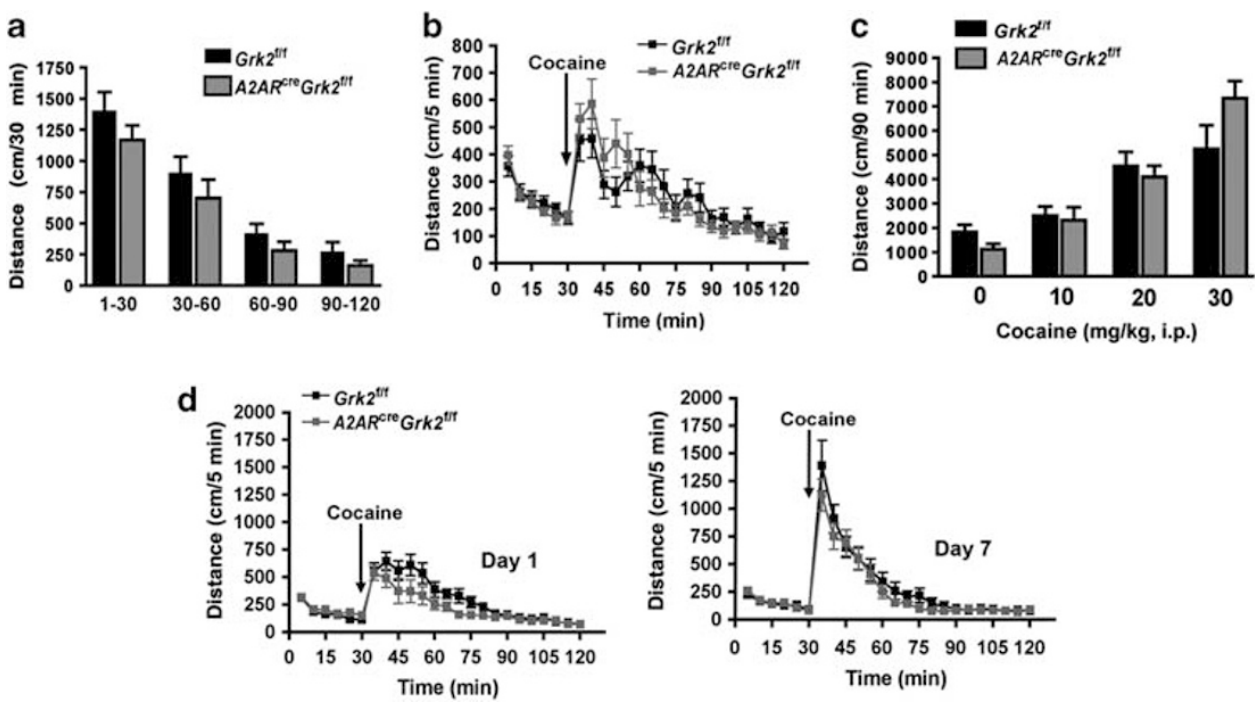

Figure 8 Deletion of GRK2 from A2AR-expressing neurons does not alter basal locomotor activity or sensitivity to cocaine. (a and b) Spontaneous activity (analyzed in 30-min intervals over a 2-h period) or cocaine-induced (20 mg/kg, i.p.) locomotion of Grk ${ }^{\mathrm{f} / \mathrm{f}}$ and $A 2 A R^{\mathrm{cre}} \mathrm{Grk} 2^{\mathrm{f} / \mathrm{f}}$ mice $($ vehicle, $n=13-16$ mice per group; cocaine, $n=15$ mice per group). (c) The sum of distance travelled by Grk $2^{\mathrm{f} / \mathrm{f}}$ and A2AR ${ }^{\mathrm{cre}} \mathrm{Grk} 2^{\mathrm{f} / \mathrm{f}}$ mice postinjection of vehicle or cocaine ( $n=8-16$ mice per group). (d) Cocaine sensitization in Grk $2^{\mathrm{f} / \mathrm{f}}$ and $A 2 A R^{c r e} G r k 2^{\mathrm{f} / \mathrm{f}}$ mice $(n=13-16$ mice for each group). Locomotor activity in cocainetreated $(20 \mathrm{mg} / \mathrm{kg}$, i.p.) mice on days I and 7 are shown.

\section{DISCUSSION}

Although previous studies have implicated GRK2 as an essential mediator of DA receptors in vitro, no investigations to date have examined whether the deficiency of this kinase in the mature brain alters DA receptor function or animal behaviors classically associated with the actions of DA. Here we used a genetic strategy to dissect GRK2 function within the mammalian brain and present evidence in support of a cell-type-specific role for GRK2 in the control of spontaneous locomotion, DA neurotransmission, D1R signaling, D2 autoreceptor function, and the behavioral response to psychostimulants. Collectively, our behavioral, biochemical, and electrophysiological results (largely summarized in Supplementary Table S2) provide novel mechanistic insight into DA receptor function in vivo and the actions of psychostimulant drugs in the murine brain. Although our current efforts were arguably DA-centric, it is plausible that GRK2 deficiency alters the function of additional GPCRs within the studied neuronal populations. This possibility should be examined in greater detail in future studies.

Earlier work with GRK5 and GRK6 germline KO mice revealed a very modest phenotype in unchallenged animals, suggesting that these kinases have little impact on diverse physiological processes under basal conditions (Gainetdinov et al, 2003; Gainetdinov et al, 1999). Similar to these findings, we observed no overt behavioral phenotype in drug-naive mice lacking GRK2 in either cholinergic (Daigle and Caron, 2012) or D1R-expressing neurons (present study). In contrast, the selective deletion of GRK2 in D2R-expressing neurons resulted in increased spontaneous locomotor activity, decreased apomorphine-induced vertical activity, and impaired habituation to a novel environment (data not shown). Basal hyperactivity was also observed in mice lacking GRK2 in DA neurons, but interestingly, not in mice with GRK2 deficiency in postsynaptic A2AR-expressing striatopallidal MSNs. The similar impairment in baseline locomotion between conditional KO mice (ie, $D 2 R^{\text {cre }} G r k 2^{\mathrm{f} / \mathrm{f}}$ mice vs $D A T^{\mathrm{cre}} G r k 2^{\mathrm{f} / \mathrm{f}}$ mice) strongly suggests that the hyperactivity phenotype of $D 2 R^{\text {cre }} G r k 2^{\text {f/f }}$ mice is caused by the loss of GRK2 in DA neurons.

Psychostimulant drugs such as cocaine promote robust increases in extracellular DA levels, resulting in enhanced DA receptor signaling and elevated locomotor activity. Because D1 and D2 receptors have a vital role in mediating the locomotor-stimulating effects of cocaine (Chausmer and Katz, 2001; Xu et al, 1994), and because GRK2 can regulate these receptors in vitro (Ito et al, 1999; Iwata et al, 1999; Namkung et al, 2009a; 2009b; Sedaghat and Tiberi, 2011; Tiberi et al, 1996), we hypothesized that GRK2 may regulate behavioral sensitivity to cocaine. Here we report that the deletion of GRK2 in D1R- and D2R-expressing neurons causes opposite effects on acute cocaine-induced locomotion, resulting in hypersensitive or hyposensitive mice, respectively. Interestingly, while all cocaine-mediated effects remained intact following deletion of GRK2 from A2AR-expressing striatopallidal MSNs (present study) or cholinergic neurons (Daigle and Caron, 2012), mice with GRK2 deficiency in DA neurons were also markedly less sensitive to the acute effects of cocaine. Collectively, these results strongly suggest that the reduced sensitivity of $D 2 R^{\text {cre }} G r k 2^{\mathrm{f} / \mathrm{g}}$ mice to cocaine is primarily due to the loss of GRK2 function in DA neurons.

Sensitization to the locomotor-stimulating effects of cocaine was also dramatically reduced by the deficiency of GRK2 in D2R-expressing neurons, but unlike for spontaneous and acute cocaine-induced locomotion, this behavioral impairment was not recapitulated in $D A T^{\mathrm{cre}} G r k 2^{\mathrm{f} / \mathrm{f}}$ or in $A 2 A R^{\mathrm{cre}} G r k 2^{\mathrm{f} / \mathrm{f}}$ mice. These results suggest that GRK2 function in D2R-expressing neurons outside of the striatum may be required for the full expression of behavioral 
sensitization to cocaine. Although further studies are still needed to pinpoint a contributing neuronal population, one promising candidate brain region is the medial prefrontal cortex (mPFC). Beyer and Steketee $(2000,2002)$ reported that quinpirole infusion into the mPFC blocks acute cocaine-induced locomotor activity and sensitization, suggesting that cortical D2R activation negatively regulates the actions of cocaine. Their behavioral results essentially phenocopy what we observe in $D 2 R^{\text {cre }} G r k 2^{\mathrm{f} / \mathrm{f}}$ mice, raising the possibility that increased activity of cortical D2Rs may also contribute to the reduction in the cocaine-induced effects in these conditional $\mathrm{KO}$ animals.

Deletion of GRK2 from D1R-expressing neurons caused a robust increase in striatal DA release and uptake in drugnaive mice. Particularly intriguing was the dramatic increase in $V_{\max }$ levels in these mice, because the rate of uptake here was similar to that observed in control animals exposed to cocaine (data not shown). One explanation for these effects is that the loss of GRK2 in this neuronal population causes an increase in the membrane-associated levels of DAT in the striatum. This perturbation could presumably also enhance DA release, because DA recycling into synaptic vesicles should also be augmented in response to a protracted increase in surface DAT levels. The initial increase in cell-surface DAT levels may be caused by elevated glutamate levels in the VTA that result from increased activity of D1Rs located on afferent glutamatergic terminals originating from forebrain regions (Kalivas and Duffy, 1995; Lu et al, 1997; Sesack and Pickel, 1992). Enhanced glutamate release directly onto DA neurons may increase neuronal firing frequency, which would thereby result in enhanced striatal DA release. If this were the case, cell-surface DAT levels may increase to compensate for the chronic elevation of extracellular DA levels. We also cannot exclude the possibility that GRK2 deletion altered the activity of additional GPCRs in this neuronal population, and these potential perturbations contributed to the profound neurochemical phenotype. In addition to these baseline alterations, enhanced DA release in response to acute cocaine exposure was also observed in striatal slices from $D 1 R^{\text {cre }} G r k 2^{\mathrm{f} / \mathrm{f}}$ mice. This observation strongly suggests that locomotor supersensitivity to cocaine may be due to elevated drug-induced DA release in the striatum of $D 1 R^{\mathrm{cre}} \mathrm{Grk} 2^{\mathrm{f} / \mathrm{f}}$ mice.

In contrast, the elimination of GRK2 from D2R-expressing neurons caused a significant reduction in striatal DA release under basal conditions. Remarkably, we found that this depression could be completely reversed by application of sulpiride, a classical D2R antagonist. These results demonstrate that GRK2 deficiency in D2R-expressing neurons leads to overactivity of presynaptic D2 autoreceptors, which thereby results in the persistent suppression of DA release from striatal DA terminals. Enhanced D2 autoreceptor activity may be due to impaired GRK2mediated desensitization of these presynaptic receptors. Importantly, the absence of GRK6 has also been reported to enhance striatal D2R activity (Gainetdinov et al, 2003), but in contrast to the present findings, this work implicated postsynaptic D2Rs as the principal physiological target of GRK6. Taken together, these data provide the first evidence that the regulation of presynaptic autoreceptors by GRKs occurs in a similar manner to the regulation of postsynaptic receptors, albeit by different GRKs. Furthermore, while it is now evident that multiple GRKs can regulate DA receptors in vivo, GRK2- and GRK6-mediated regulation exhibit neuronal specificity and regulate distinct populations of striatal D2Rs (presynaptic vs postsynaptic).

The reduced behavioral sensitivity of $D 2 R^{\mathrm{cre}} G r k 2^{\mathrm{f} / \mathrm{f}}$ mice to cocaine was paralleled by changes at the neurochemical level. Here we observed that repeated cocaine treatment of $D 2 R^{\text {cre }} G r k 2^{\mathrm{f} / \mathrm{f}}$ mice was less effective at promoting the expected sensitized increase in striatal DA release. Additionally, we uncovered a dramatic impairment in cocainemediated uptake inhibition in the striatum of both drug-naive and drug-sensitized animals. Therefore, in addition to the regulation of D2 autoreceptors, GRK2 deficiency may also impact the sensitivity of DAT for cocaine and/or the availability of releasable DA. Detailed investigation will be required in future work to establish the entire collection of presynaptic targets affected by GRK2 deletion.

Mice with the genetic deletion of D2 autoreceptors exhibit hyperactivity when placed in a novel environment and are hypersensitive to the acute locomotor-stimulating effects of cocaine (Anzalone et al, 2012; Bello et al, 2011). Our results are partially consistent with these earlier findings in that the reverse perturbation, increased D2 autoreceptor activity, causes reduced locomotor sensitivity to cocaine. However, both $D 2 R^{\text {cre }} G r k 2^{\mathrm{f} / \mathrm{f}}$ mice and D2 autoreceptor-deficient mice exhibited hyperactivity when exposed to a novel environment. This seemingly paradoxical phenotype in baseline locomotor activity between $D 2 R^{\mathrm{cre}} G r k 2^{\mathrm{f} / \mathrm{f}}$ mice and D2 autoreceptor-deficient mice is likely due to the constitutive deletion of GRK2 from D2R-expressing cells, which could lead to multiple aberrant physiological processes in diverse brain regions (eg, potential cortical D2R hyperactivity in the mPFC). It is also important to note that both chronic hyperdopaminergia and hypodopaminergia cause a remarkable array of adaptive changes at the molecular level, including alterations in DA synthesis, storage, and DA receptor levels and functioning, as well as distinct behavioral impairments (Giros et al, 1996; Jones et al, 1999; Salahpour et al, 2008; Sotnikova et al, 2005). Therefore, the lack of an opposite behavioral outcome in this context (ie, spontaneous locomotion) may also be due to divergent compensatory mechanisms that exist between genetic models and result from alterations in extracellular DA levels.

The mystery of GRK2 function in the adult brain is beginning to become unraveled. This pursuit has been greatly aided by genetic methods that improve on the traditional gene KO approach and allow for the cell-typespecific deletion of proteins in the mature brain. Here we provide evidence that GRK2 deficiency in select neuronal populations in adult animals profoundly alters cocainedependent behaviors and striatal DA neurotransmission. Intriguingly, we found that the deletion of GRK2 in D1R- and D2R-expressing neurons differentially affects locomotor sensitivity to cocaine and striatal DA dynamics. D2 autoreceptor function was also significantly impaired in the absence of GRK2, suggesting that this receptor is robustly regulated by GRK2 under physiological conditions. Taken together, it appears that GRK2 has a vital role in the central DA system and thus may represent a novel therapeutic target for DA-related brain disorders. 


\section{FUNDING AND DISCLOSURE}

This work was supported in part by NIH grants DA030026 (to TLD), MH073853, U19-MH082441, and P30-DA029925 (to MGC), DA031791 (to MJF), DA024095 (to SRJ), and DA030161 (to SRJ). MGC has received funds for sponsored research agreements unrelated to this work from Forest Laboratories and F. Hoffmann La Roche as well as consulting fees from Omeros Corporation. MGC has also received compensation in the form of honoraria for lecturing at various scientific meetings and academic institutions. RRG is supported in part by research grants from F. Hoffmann La-Roche (Basel, Switzerland) and St Petersburg State University (St Petersburg, Russia) grant no. 1.38.201.2014. None of the above presents any conflicts of interest with the results described in the present paper. The other authors declare no conflict of interest.

\section{ACKNOWLEDGEMENTS}

We thank Dr Gerald Dorn II from the Washington University (St Louis, MO) for generously making the floxed Grk2 mice available for these studies, Xiuqin Zhang and Katherine Harley for outstanding assistance with the mouse husbandry, and Dr Jonathan Ting for comments on the manuscript.

\section{REFERENCES}

Ahmed MR, Bychkov E, Gurevich VV, Benovic JL, Gurevich EV (2008a). Altered expression and subcellular distribution of GRK subtypes in the dopamine-depleted rat basal ganglia is not normalized by l-DOPA treatment. J Neurochem 104: 1622-1636.

Ahmed MR, Gurevich VV, Dalby KN, Benovic JL, Gurevich EV (2008b). Haloperidol and clozapine differentially affect the expression of arrestins, receptor kinases, and extracellular signal-regulated kinase activation. J Pharmacol Exp Ther 325: 276-283.

Anzalone A, Lizardi-Ortiz JE, Ramos M, De Mei C, Hopf FW, Iaccarino C et al (2012). Dual control of dopamine synthesis and release by presynaptic and postsynaptic dopamine D2 receptors. J Neurosci 32: 9023-9034.

Bateup HS, Santini E, Shen W, Birnbaum S, Valjent E, Surmeier DJ et al (2010). Distinct subclasses of medium spiny neurons differentially regulate striatal motor behaviors. Proc Natl Acad Sci USA 107: 14845-14850.

Bateup HS, Svenningsson P, Kuroiwa M, Gong S, Nishi A, Heintz N et al (2008). Cell type-specific regulation of DARPP-32 phosphorylation by psychostimulant and antipsychotic drugs. Nat Neurosci 11: 932-939.

Beaulieu JM, Gainetdinov RR (2011). The physiology, signaling, and pharmacology of dopamine receptors. Pharmacol Rev 63: 182-217.

Beaulieu JM, Sotnikova TD, Marion S, Lefkowitz RJ, Gainetdinov RR, Caron MG (2005). An Akt/beta-arrestin 2/PP2A signaling complex mediates dopaminergic neurotransmission and behavior. Cell 122: 261-273.

Beaulieu JM, Sotnikova TD, Yao WD, Kockeritz L, Woodgett JR, Gainetdinov RR et al (2004). Lithium antagonizes dopaminedependent behaviors mediated by an AKT/glycogen synthase kinase 3 signaling cascade. Proc Natl Acad Sci USA 101: 5099-5104.

Beaulieu JM, Tirotta E, Sotnikova TD, Masri B, Salahpour A, Gainetdinov RR et al (2007). Regulation of Akt signaling by D2 and D3 dopamine receptors in vivo. J Neurosci 27: 881-885.
Bello EP, Mateo Y, Gelman DM, Noain D, Shin JH, Low MJ et al (2011). Cocaine supersensitivity and enhanced motivation for reward in mice lacking dopamine D2 autoreceptors. Nat Neurosci 14: 1033-1038.

Beyer CE, Steketee JD (2000). Intra-medial prefrontal cortex injection of quinpirole, but not SKF 38393, blocks the acute motor-stimulant response to cocaine in the rat. Psychopharmacology (Berl) 151: 211-218.

Beyer CE, Steketee JD (2002). Cocaine sensitization: modulation by dopamine D2 receptors. Cereb Cortex 12: 526-535.

Bezard E, Gross CE, Qin L, Gurevich VV, Benovic JL, Gurevich EV (2005). L-DOPA reverses the MPTP-induced elevation of the arrestin2 and GRK6 expression and enhanced ERK activation in monkey brain. Neurobiol Dis 18: 323-335.

Brown JM, Hanson GR, Fleckenstein AE (2001). Cocaine-induced increases in vesicular dopamine uptake: role of dopamine receptors. J Pharmacol Exp Ther 298: 1150-1153.

Bychkov E, Zurkovsky L, Garret MB, Ahmed MR, Gurevich EV (2012). Distinct cellular and subcellular distributions of $G$ protein-coupled receptor kinase and arrestin isoforms in the striatum. PLoS One 7: e48912.

Chausmer AL, Katz JL (2001). The role of D2-like dopamine receptors in the locomotor stimulant effects of cocaine in mice. Psychopharmacology (Berl) 155: 69-77.

Daigle TL, Caron MG (2012). Elimination of GRK2 from cholinergic neurons reduces behavioral sensitivity to muscarinic receptor activation. J Neurosci 32: 11461-11466.

Daigle TL, Wetsel WC, Caron MG (2011). Opposite function of dopamine D1 and $N$-methyl-D-aspartate receptors in striatal cannabinoid-mediated signaling. Eur J Neurosci 34: 1378-1389.

Daws LC, Callaghan PD, Moron JA, Kahlig KM, Shippenberg TS, Javitch JA et al (2002). Cocaine increases dopamine uptake and cell surface expression of dopamine transporters. Biochem Biophys Res Commun 290: 1545-1550.

Gainetdinov RR, Bohn LM, Sotnikova TD, Cyr M, Laakso A, Macrae AD et al (2003). Dopaminergic supersensitivity in G protein-coupled receptor kinase 6-deficient mice. Neuron 38: 291-303.

Gainetdinov RR, Bohn LM, Walker JK, Laporte SA, Macrae AD, Caron MG et al (1999). Muscarinic supersensitivity and impaired receptor desensitization in $\mathrm{G}$ protein-coupled receptor kinase 5-deficient mice. Neuron 24: 1029-1036.

Giros B, Jaber M, Jones SR, Wightman RM, Caron MG (1996). Hyperlocomotion and indifference to cocaine and amphetamine in mice lacking the dopamine transporter. Nature 379: 606-612.

Guzman MS, De Jaeger X, Raulic S, Souza IA, Li AX, Schmid S et al (2011). Elimination of the vesicular acetylcholine transporter in the striatum reveals regulation of behaviour by cholinergicglutamatergic co-transmission. PLoS Biol 9: e1001194.

Ito K, Haga T, Lameh J, Sadee W (1999). Sequestration of dopamine D2 receptors depends on coexpression of G-proteincoupled receptor kinases 2 or 5. Eur J Biochem 260: 112-119.

Iwata K, Ito K, Fukuzaki A, Inaki K, Haga T (1999). Dynamin and rab5 regulate GRK2-dependent internalization of dopamine D2 receptors. Eur J Biochem 263: 596-602.

Jaber M, Koch WJ, Rockman H, Smith B, Bond RA, Sulik KK et al (1996). Essential role of beta-adrenergic receptor kinase 1 in cardiac development and function. Proc Natl Acad Sci USA 93: 12974-12979.

Jones SR, Gainetdinov RR, Hu XT, Cooper DC, Wightman RM, White FJ et al (1999). Loss of autoreceptor functions in mice lacking the dopamine transporter. Nat Neurosci 2: 649-655.

Kalivas PW, Duffy P (1995). D1 receptors modulate glutamate transmission in the ventral tegmental area. J Neurosci 15(7 Pt 2): 5379-5388.

Kennedy RT, Jones SR, Wightman RM (1992). Dynamic observation of dopamine autoreceptor effects in rat striatal slices. J Neurochem 59: 449-455. 
Lu XY, Churchill L, Kalivas PW (1997). Expression of D1 receptor mRNA in projections from the forebrain to the ventral tegmental area. Synapse 25: 205-214.

Matkovich SJ, Diwan A, Klanke JL, Hammer DJ, Marreez Y, Odley AM et al (2006). Cardiac-specific ablation of G-protein receptor kinase 2 redefines its roles in heart development and beta-adrenergic signaling. Circ Res 99: 996-1003.

McLaughlin JP, Myers LC, Zarek PE, Caron MG, Lefkowitz RJ, Czyzyk TA et al (2004). Prolonged kappa opioid receptor phosphorylation mediated by G-protein receptor kinase underlies sustained analgesic tolerance. J Biol Chem 279: 1810-1818.

Namkung Y, Dipace C, Javitch JA, Sibley DR (2009a). G proteincoupled receptor kinase-mediated phosphorylation regulates post-endocytic trafficking of the D2 dopamine receptor. J Biol Chem 284: 15038-15051.

Namkung Y, Dipace C, Urizar E, Javitch JA, Sibley DR (2009b). G protein-coupled receptor kinase-2 constitutively regulates D2 dopamine receptor expression and signaling independently of receptor phosphorylation. J Biol Chem 284: 34103-34115.

Premont RT, Gainetdinov RR (2007). Physiological roles of G protein-coupled receptor kinases and arrestins. Annu Rev Physiol 69: 511-534.

Salahpour A, Ramsey AJ, Medvedev IO, Kile B, Sotnikova TD, Holmstrand $\mathrm{E}$ et al (2008). Increased amphetamine-induced hyperactivity and reward in mice overexpressing the dopamine transporter. Proc Natl Acad Sci USA 105: 4405-4410.

Schroeder JA, McCafferty MR, Unterwald EM (2009). Regulation of dynamin 2 and $G$ protein-coupled receptor kinase 2 in rat nucleus accumbens during acute and repeated cocaine administration. Synapse 63: 863-870.

Sedaghat K, Tiberi M (2011). Cytoplasmic tail of D1 dopaminergic receptor differentially regulates desensitization and phosphorylation by $\mathrm{G}$ protein-coupled receptor kinase 2 and 3. Cell Signal 23: 180-192.

Sesack SR, Pickel VM (1992). Prefrontal cortical efferents in the rat synapse on unlabeled neuronal targets of catecholamine terminals in the nucleus accumbens septi and on dopamine neurons in the ventral tegmental area. J Comp Neurol 320: 145-160.
Sotnikova TD, Beaulieu JM, Barak LS, Wetsel WC, Caron MG, Gainetdinov RR (2005). Dopamine-independent locomotor actions of amphetamines in a novel acute mouse model of Parkinson disease. PLoS Biol 3: e271.

Srinivas S, Watanabe T, Lin CS, William CM, Tanabe Y, Jessell TM et al (2001). Cre reporter strains produced by targeted insertion of EYFP and ECFP into the ROSA26 locus. BMC Dev Biol 1: 4

Tiberi M, Nash SR, Bertrand L, Lefkowitz RJ, Caron MG (1996). Differential regulation of dopamine D1A receptor responsiveness by various $\mathrm{G}$ protein-coupled receptor kinases. J Biol Chem 271: 3771-3778.

Urs NM, Snyder JC, Jacobsen JP, Peterson SM, Caron MG (2012). Deletion of GSK3beta in D2R-expressing neurons reveals distinct roles for beta-arrestin signaling in antipsychotic and lithium action. Proc Natl Acad Sci USA 109: 20732-20737.

Wang H, Wu LJ, Kim SS, Lee FJ, Gong B, Toyoda H et al (2008). FMRP acts as a key messenger for dopamine modulation in the forebrain. Neuron 59: 634-647.

Wightman RM, Amatore C, Engstrom RC, Hale PD, Kristensen EW, Kuhr WG et al (1988). Real-time characterization of dopamine overflow and uptake in the rat striatum. Neuroscience 25: 513-523.

Wu Q, Reith ME, Wightman RM, Kawagoe KT, Garris PA (2001). Determination of release and uptake parameters from electrically evoked dopamine dynamics measured by real-time voltammetry. J Neurosci Methods 112: 119-133.

Xu M, Hu XT, Cooper DC, Moratalla R, Graybiel AM, White FJ et al (1994). Elimination of cocaine-induced hyperactivity and dopamine-mediated neurophysiological effects in dopamine D1 receptor mutant mice. Cell 79: 945-955.

Yorgason JT, Espana RA, Jones SR (2011). Demon voltammetry and analysis software: analysis of cocaine-induced alterations in dopamine signaling using multiple kinetic measures. J Neurosci Methods 202: 158-164.

Zhuang X, Masson J, Gingrich JA, Rayport S, Hen R (2005). Targeted gene expression in dopamine and serotonin neurons of the mouse brain. J Neurosci Methods 143: 27-32.

Supplementary Information accompanies the paper on the Neuropsychopharmacology website (http://www.nature.com/npp) 